\title{
Homossexualidade masculina: comportamento, orientação e identidade
}

\author{
José Estevam Salgueiro' \\ Universidade Presbiteriana Mackenzie, São Paulo - SP - Brasil
}

\begin{abstract}
Resumo: A pesquisa aborda a homossexualidade masculina a partir dos aspectos comportamento, orientação e identidade, mostrando que a presença desses componentes não ocorre de forma conjunta e concomitante, obrigatoriamente, tendo em vista manifestações da homossexualidade masculina. Dessa forma, este trabalho procura demonstrar ser possível encontrar situações humanas em que pelo menos um dos parceiros não possua orientação homossexual; bem como situações em que os atores envolvidos não se reconhecem como homossexuais e situação em que a presença de orientação homossexual não resulta em comportamento. Mesmo ausente algum desses três componentes, a ocorrência poderá ser considerada uma manifestação de homossexualidade. A pesquisa usa, como dados, narrativas de homens ocorridas em consultório de psicologia e os textos $\mathrm{O}$ beijo no asfalto, de Nelson Rodrigues, e $\mathrm{O}$ beijo da mulher-aranha, de Manuel Puig. Esta pesquisa buscou uma maior compreensão desses fenômenos e também contribuir para a superação, por meio do entendimento, dos mecanismos do preconceito.
\end{abstract}

Palavras-chave: preconceito; homossexualidade masculina; orientação sexual; comportamento; identidade.

\section{MALE HOMOSEXUALITY: BEHAVIOR, ORIENTATION AND IDENTITY}

\begin{abstract}
This research deals with the male homosexuality as seen from the aspects behavior, orientation and identity, showing that these aspects are not necessarily altogether present in all manifestations of the male homosexuality. Hence, as hypothesis, this work considers it to be possible to find human situations where: at least one of the partners is not homosexual oriented; the actors involved not always will recognize themselves as homosexuals; and the presence of a homosexual orientation does not result in a homosexual behavior. Even when one of these three dimensions is not present in the occurrence, it might be considered an authentic homosexual manifestation. This research uses as field data, narratives of men taken at a psychology clinic and the texts $\mathrm{O}$ beijo no asfalto, of Nelson Rodrigues, and Kiss of the spider woman, of Manuel Puig. This research sought a better understanding of these phenomena and also contribute to overcoming, through understanding the mechanisms of prejudices.
\end{abstract}

Keywords: prejudices; male homosexuality; sexual orientation; behavior; identity.

\section{HOMOSEXUALIDAD MASCULINA: COMPORTAMIENTO, ORIENTACIÓN YIDENTIDAD}

Resumen: La investigación aborda la homosexualidad masculina a partir de los aspectos comportamiento, orientación y identidad, y muestra que la presencia de estos componentes no se produce de forma conjunta y simultánea, necesariamente, en manifestaciones de la homosexualidad masculina. Es posible encontrar situaciones en que al menos una pareja no tiene una orientación homosexual, o que ella está fuera del campo

${ }^{1}$ Endereço para correspondência: José Estevam Salgueiro, Universidade Presbiteriana Mackenzie, Rua da Consolação 896, Consolação, São Paulo - SP - Brasil. CEP: 01302-907. E-mail: joseestevam.salgueiro@mackenzie.br. 
de la conciencia; y situaciones en que los actores involucrados no se reconocen como homosexuales y situaciones en que la presencia de la orientación no resulta en comportamiento. Mismo con la ausencia de cualquiera de estos tres componentes, una manifestación de la homosexualidad podría ser considerada. La investigación utiliza como datos de campo, narrativas de los hombres se dieron en la clínica psicología clínica. El trabajo también utiliza el texto $O$ beijo no asfalto, de Nelson Rodrigues y $O$ beijo da mulher-aranha, de Manuel Puig. Esta investigación busca una mejor comprensión de estos fenómenos y también contribuir a la superación, a través de la comprensión de los mecanismos de lo prejuicio.

Palabras clave: prejuicio; homosexualidad masculina; orientación sexual; comportamiento; identidad.

A superação da chamada "crise da masculinidade" demanda a definição de um novo perfil do masculino, e esse novo perfil deve eliminar os medos e as inseguranças dos homens quanto à sua própria sensibilidade e a assunção de papéis e funções até então considerados menos viris. Essa crise vem da reconfiguração do papel da mulher nas relações. Até depois da Segunda Guerra Mundial, os homens tinham "uma visão clara do que deviam ser e das responsabilidades masculinas", mas "durante a década de 1960 surgiu outro tipo de homem" (Bly, 2004, p. 2).

O medo que o homem/macho tem da homossexualidade é mais um agravante no contexto dessa crise: perder as nítidas fronteiras entre o que é masculino e o que é feminino apavora. A homossexualidade traz esse pânico: é o homem/macho que não é mais homem/macho, ou no mínimo já não é mais tão homem/macho. É o homem/ macho que começa a ser mulher, por desejar e se relacionar com outro homem.

[...] ser homem significa não ser homossexual. Ser homem significa não ser feminino; não ser homossexual; não ser dócil, dependente ou submisso; não ser efeminado na aparência física ou nos gestos; não ter relações sexuais nem relações muito íntimas com outros homens; não ser impotente com as mulheres (Badinter, 1993, p. 117).

Essa "crise da identidade masculina" que, entre outras questões, trouxe para a superfície a necessidade e o medo da sensibilidade masculina trouxe ao mesmo tempo muita angústia e sofrimento para os homens e as mulheres. Os parâmetros para os relacionamentos conjugais já não são mais os mesmos e, no entanto, novos parâmetros ainda não foram consolidados ou compartilhados, e isso gerou muitas dificuldades nesses relacionamentos. A sensibilidade masculina, ou no mínimo a expressão dessa sensibilidade, está diretamente articulada com o medo da homossexualidade, a homofobia.

A homossexualidade suscita em alguns homens (em particular nos rapazes) um temor que não tem equivalente entre as mulheres. Este temor se traduz por atitudes de esquivamento, agressividade ou repulsa não dissimulada. [...] Ela (a homofobia) se liga a outros medos, em particular ao medo da igualdade entre os sexos. Os homofobos[sic] são pessoas conservadoras, rígidas, favoráveis à manutenção dos papéis sexuais tradicionais [...] (Badinter, 1993, p. 118). 
Quando a autora coloca que o medo e o ódio à homossexualidade, à homofobia, estão relacionados ao medo à igualdade entre os sexos está revelando que esse medo e esse ódio passam pelo desprezo às mulheres, pelo desprezo a quem é sexualmente "submetido", a quem recebe o coito. Além disso, Badinter (1993, p. 118) levanta possíveis hipóteses da origem da homofobia, descrevendo possíveis articulações com um tipo determinado de personalidade:

De fato, a homofobia remete ao temor secreto dos próprios desejos homossexuais. Ver um homem efeminado desperta enorme angústia em muitos homens, pois desencadeia neles uma tomada de consciência de suas próprias características femininas, como a passividade e a sensibilidade, que eles consideram um sinal de fraqueza.

Além dos aspectos levantados pela autora, a homofobia também deixa transparecer um desprezo a quem é sexualmente "submetido", um desprezo ao homem que, abandonando sua posição de homem, assume a posição que cabe à mulher (Bourdieu, 2014; Trevisan, 1998; Badinter, 1993).

Outro aspecto que também passa pela questão da homossexualidade e pelo pânico de muitos homens de serem considerados ou vistos como homossexuais, frouxos ou maricas é a questão da violência, já que a força e a violência foram associadas à masculinidade. Ser homem é ser forte, é ser violento. Há a história de um rapaz de 26 anos, habitante de uma pequena cidade próxima à capital do Rio Grande do Norte, que, ante os comentários da cidade de que "não seria homem", acabou, para provar sua masculinidade, sua macheza, cometendo inúmeros assassinatos de membros de sua família para exibir, e dessa forma provar, sua masculinidade (Trevisan, 1998).

Uma das poucas marcas restantes fortemente masculinas, segundo Nolasco (2006), é a violência, e assim os homens se fazem violentos para serem homens, pois acreditam que os homens/machos sejam necessariamente agressivos. A agressividade legitima a posição masculina e a masculinidade é comprovada pela agressividade dos machos. Ser agressivo é não ser feminino, portanto é ser-se masculino. Ser agressivo é não ser delicado ou gentil, não ser afeminado, é não ser homossexual; em resumo, ser agressivo é ser homem/macho. Passemos a palavra ao autor:

No Ocidente, a masculinidade não vem facilmente; ela é conquistada através de muito esforço, existindo entre a representação masculina e a violência uma estreita relação, uma vez que brigar é, em última instância, uma forma de o sujeito defender sua imagem de homem (Nolasco, 2006, p. 97).

O tema da sexualidade humana é amplo e permanente. Também é ampla a discussão sobre as determinantes e as variantes dessa dimensão do humano. O presente estudo propõe abordar a questão da sexualidade humana na sua variante da homossexualidade masculina, utilizando-se de três dimensões constituintes da sexualidade: comportamento, orientação e identidade e, dessa forma, contribuir para o entendi- 
mento desse universo e, principalmente, indicar possibilidades para o trato e superação das dificuldades e consequências decorrentes do tema.

O entendimento da homossexualidade a partir dessas três dimensões permite uma organização conceitual das manifestações do tema da homossexualidade masculina, de tal forma que cada uma das referidas dimensões - orientação, comportamento e identidade - possa ser reconhecida e considerada isoladamente.

Em variadas oportunidades, cada um desses elementos é tratado como se fosse a própria homossexualidade em sua totalidade. Muitas vezes, em contextos psicanalíticos, por exemplo, diz-se homossexualidade para se referir quase que exclusivamente ao desejo homossexual, à orientação homossexual. Em outras situações, percebe-se que o termo homossexual ou homossexualidade pretende referir-se ao comportamento, à prática de atos com pessoas do mesmo sexo. Por exemplo, quando se trata da homossexualidade entre os gregos, está se falando de atos sexuais praticados entre pessoas do mesmo sexo, até porque na cultura grega nem mesmo a palavra homossexual existia, portanto poderia ser impreciso usar-se o termo classificatório homossexual para configurar a relação entre pessoas do mesmo sexo nessa época histórica (Foucault, 2014; Dover, 2007).

Os preconceitos relativos à sexualidade (e, principalmente, aqueles relativos à homossexualidade) dar-se-ão sempre em contextos de repressão e normatização excessiva e autoritária; serão característicos de personalidades altamente hierarquizadas, ou seja, os preconceitos são resultados de processos cognitivos mais primários e estarão presentes em estruturações cognitivas de menor complexidade (estruturações cognitivas que não atingem um nível mais complexo de elaboração e operam de modo mais linear ou bipolar). Os preconceitos estarão presentes em pessoas e contextos regidos muito mais por medo, culpa e vergonha.

Estudos recentes demonstram que o tema da homossexualidade, muito embora tenha se tornado mais exposto, tanto na mídia de grande massa quanto nos meios jurídicos e acadêmicos, ainda se mantém cercado de elementos de preconceito e discriminação, mesmo tendo havido significativos avanços alcançados na esfera jurídica, como o reconhecimento da união homoafetiva (Lopes, 2014; Barroso, 2011) e, na esfera social, como o reconhecimento da existência e denúncia da homofobia em diversos contextos (Santos, 2013; Pereira, Alfaia, Souza \& Lima, 2014; Marques, 2014; Diniz, Carrieri, Gandra, \& Bicalho, 2013; Almeida \& Soares, 2012).

Os mecanismos e procedimentos de repressão se fazem notar primeira e mais fortemente na contenção e punição do comportamento ou ato homossexual, dimensão efetiva e objetiva da sexualidade ou, até mesmo, diante de qualquer ato ou comportamento assemelhado ou que permita a menor insinuação de expressão homossexual. A partir daí, da avaliação e, se for o caso, da punição dos comportamentos considerados desviantes (fora dos padrões paradigmáticos) se constroem os conceitos e consequentemente os preconceitos relativos à orientação e à identidade. São justamente esses procedimentos culturais, esses procedimentos repressivos e de avaliação estética de 
estranheza que propiciam que haja desencontro, na dinâmica pessoal dos indivíduos e na própria elaboração coletiva, entre orientação, identidade e comportamento sexual.

Esta pesquisa parte por considerar possível a ocorrência de situações ou episódios considerados homossexuais, nos quais não obrigatoriamente estarão presentes, em conjunto, estes três componentes: comportamento, orientação e identidade. Considera que são possíveis vivências, relatos ou situações homossexuais nas quais, em pelo menos um dos parceiros envolvidos, um ou mais desses aspectos não estejam presentes, e mesmo ausente alguma dessas três dimensões, a situação, ocorrência ou episódio poderá, operacional e autenticamente, ser considerada uma manifestação de homossexualidade. Dessa forma, é possível nos defrontarmos com situações humanas em que:

1. pelo menos um dos parceiros implicados não possua orientação homossexual, ou que essa orientação esteja negada, recalcada, deslocada ou sublimada (fora do campo da consciência);

2. nem sempre ambos os atores envolvidos na situação reconhecer-se-ão como homossexuais ou, mesmo que seu comportamento seja um comportamento homossexual, poderão desconsiderar ou negar essa forma de sua sexualidade, esse comportamento, na dimensão de suas identidades;

3. a existência, a presença e o reconhecimento da orientação homossexual não resultam obrigatoriamente em comportamento homossexual, não conduzem à ação como seria de supor dentro de uma tradição na qual o desejo conduz ao ato.

E todas essas situações podem ser consideradas autenticamente homossexuais, ou seja, poder-lhe-á ser atribuída, com propriedade, essa denominação.

\section{Considerações conceituais}

\section{Sobre orientação, identidade e comportamento}

Em uma conceituação abrangente, orientação sexual refere-se à preferência sexual e amorosa do sujeito, para onde dirigem, de forma mais ou menos nítida, mais ou menos frequente ou constante, seus interesses sexuais; quais os alvos preferenciais de seu interesse sexual; e quais os objetos sexuais que estimulam, excitam, provocam prazer.

Vale lembrar que "identificar socialmente pessoas por suas preferências sexuais é uma escolha cultural, entre outras, e que tem consequências éticas e psicológicas importantes na subjetividade" (Costa, 1998a, p. 23). É justamente essa escolha cultural de nossa sociedade, essa escolha que elege a preferência e a orientação sexual do indivíduo como determinante fundamental de sua subjetividade que impõe a necessidade teórica de conhecer as origens e as causas dessa orientação, principalmente quando a orientação não segue a hegemônica. 
O fato de elegermos as inclinações sexuais como fator preponderante é uma posição histórica de nossa cultura. Com frequência, tendemos a considerar nossas escolhas culturais como as escolhas corretas, já que são vistas, muitas vezes, como as únicas possíveis, ou melhor, as únicas corretas.

A orientação sexual é o mais secreto componente da sexualidade. Em princípio, pertence exclusivamente ao sujeito e, em tese, só ele tem acesso à sua orientação sexual, no mais íntimo de sua consciência, ou no mais profundo de sua inconsciência: pode, portanto, ser ocultada dos demais. Ainda quando presente no campo da consciência, mesmo quando percebida e reconhecida pelo sujeito, a orientação homossexual pode ser tratada desvinculada dos outros componentes da sexualidade: uma pessoa que percebe em si preferências homossexuais pode tratar esse componente desmembradamente de seu comportamento e de sua identidade; mesmo que tais preferências se mostrem, internamente de forma dominante na consciência, não obrigatoriamente serão realizadas em ato.

Qualquer que seja a fundamentação conceitual ou as considerações constitutivas que se use, quando abordado, o tema da identidade engloba dois processos básicos: a diferença e a igualdade. Ser diferente "de" e ser igual "a". A identidade, portanto, pressupõe o outro, para que essa condição de igualdade e/ou de diferença possa ser estabelecida: percebemo-nos como iguais e como diferentes, conforme os grupos sociais que contatamos e interagimos. É por meio desses outros - iguais ou diferentes que o sujeito se constitui.

É muito importante observar que a identidade que o indivíduo constrói de si mesmo está diretamente vinculada ao que percebe como os outros a avaliam, ao modo como é percebido pelos outros. A identidade, nesses termos, é um fator comparativo, uma vez que remete o indivíduo a seu grupo de referência, fazendo que esse indivíduo seja "julgado" segundo os valores e critérios desse grupo, o que, na prática, significa que o indivíduo é comparado aos outros indivíduos do grupo: a identidade, portanto, é relativa à de outras pessoas ou grupos.

A própria etimologia da palavra "identidade" contém a ideia de ser igual, idêntico, em uma perspectiva em que o indivíduo é igual a si mesmo. Em termos grupais, é necessário que haja um nome que possa ser atribuído ao indivíduo, uma categoria social à qual o indivíduo possa ser referido, à qual ele possa ser aproximado ou incluído. Esses nomes que nos atribuem e que passamos, nós mesmos, a nos atribuir virão a compor nossa identidade, serão os recursos descritivos aos quais recorreremos para constituir nossa identidade.

E, por fim, de um ponto de vista eminentemente objetivo, comportamento homossexual ou homoerótico é todo e qualquer ato de caráter erótico e/ou sexual, genital ou não, realizado por pessoas do mesmo sexo biológico, ainda que, em suas subjetividades, os atores envolvidos nessas situações possam tratar tal ocorrência - tais atos e condutas - de formas diversas e variadas, e até mesmo, no limite, não considerar, por qualquer razão, tal comportamento como um comportamento homossexual. 


\section{Sobre sexualidade}

Na discussão sobre a sexualidade, algumas posições defendem uma natureza na sexualidade, segundo as quais "é a biologia que define, em última instância, a essência do masculino e do feminino" e que "todos os comportamentos humanos se explicam em termos de hereditariedade genética e de funcionamento neurônico" (Badinter, 1993, p. 23). E assim, devemos, pois, seguir e vigiar para que essa natureza seja atendida, nunca desvirtuada ou ofendida, apesar de não se ter consenso sobre qual é essa natureza. A partir daí, estereótipos são criados, difundidos e mantidos: o macho é naturalmente forte, a fêmea é naturalmente afável e submissa: afirma-se um suposto naturalismo ou determinismo no conteúdo e na forma da sexualidade. Já outras posições consideram que "não existe modelo [...] universal, válido para todos os tempos e lugares [...] não é uma essência, mas uma ideologia. [Constata-se a] extrema variabilidade dos papéis e dos estereótipos masculinos e femininos" (Badinter, 1993, pp. 27-28). O homem transcende a natureza e a natureza que traz em si. O homem nega a sua condição.

A Terra é a própria quintessência da condição humana, e a natureza terrestre, ao que sabemos, pode ser a única no universo capaz de proporcionar aos seres humanos um habitat no qual eles podem mover-se e respirar sem esforço nem artifícios. O mundo - artifício humano - separa a existência do homem de todo ambiente meramente animal; mas a vida, em si, permanece fora desse mundo artificial, e através da vida o homem permanece ligado a todos os outros organismos vivos (Arendt, 2014, p. 2).

Podemos falar de uma natureza humana forte e difusa. Forte porque permanece além das construções sociais e culturais, que podem ser definidas e compreendidas como defesas levantadas para conter ou controlar essa própria natureza. Na tentativa de conter e controlar a natureza, e a sua própria natureza, o homem constrói defesas: cultura, ciência, arte e civilização. E cada um de nós, individualmente, tem de lutar com a natureza, e vencê-la para nos tornarmos humanos. Difusa, pois mesmo sempre presente como força e tensão, não se manifesta, sob uma única forma. Ao contrário, busca diversas maneiras de se fazer presente na existência das culturas e dos indivíduos, diferenças muitas vezes discretas e sutis, porém, nítidas.

A natureza humana é o movimento que impulsiona, e não a forma que fixa esse impulso, nem a forma fixa desse impulsionar. O sexo articula novamente o homem com a natureza: mesmo que a humanidade crie múltiplas manifestações da sexualidade, sempre será sexualidade. A sexualidade é uma condição humana. Nesse desdobramento múltiplo, há algo constante e universal: a própria sexualidade. Impulso é a mobilização, possibilidade e potencialidade. 


\section{Metodologia}

Para esta pesquisa, foram organizadas 13 narrativas, a partir das falas de 13 clientes do sexo masculino, recolhidas em registros e escutas na prática do consultório de psicologia clínica, por um período de três a doze meses. Essas falas relataram práticas, fantasias, expectativas, pensamentos e considerações desses homens acerca de sua sexualidade. Essas composições organizam fragmentos relativos a comportamento, orientação e identidade, com foco na sexualidade, ainda que outras dimensões a existência permeassem e circunscrevessem essa sexualidade. Para identificá-los, já dentro da construção das narrativas, foram criadas expressões descritivas da situação, não necessariamente com as palavras deles.

Tais depoimentos, por terem ocorrido no contexto psicoterapêutico, revestem-se de autenticidade, até porque foram depoimentos espontâneos, não provocados, nem estimulados, ou solicitados, dando-se entre outras inúmeras informações acerca do cotidiano e da realidade dessas pessoas. O critério de escolha dessas narrativas foi sua pertinência ao tema e não a queixa original ou a orientação sexual dos narradores. São depoimentos e descrições da condição humana ditos no contexto de confiança e confidencialidade do consultório, o que lhes dá chancela de veracidade e consistência que o sigilo e a proposta da relação terapêutica garantem.

Narrativas que privilegiam a presença do comportamento:

1. "O homem que faz sexo com um 'homem' de verdade", com 43 anos, há dois anos mantém regularmente relações sexuais com um parceiro que é "bastante homem", na aparência e no comportamento. Tem, inclusive, atividade profissional tipicamente masculina e bastante viril: é funileiro e lustrador de carros. Mantêm contatos apenas genitais e não há qualquer troca de afeto ou afago entre eles. Comenta que "nunca teve um parceiro tão homem". Seu parceiro não se vê nem se considera homossexual ou mesmo bissexual: vê-se como exclusivamente heterossexual, pois além de manter relações frequentes com mulheres, e nas situações com "o homem que faz sexo com um 'homem' de verdade" ocupa sempre a posição "de homem" (neste contexto, significa aquele que penetra e que não é penetrado) e, além disso, também por não terem, mesmo durante o ato sexual, nenhuma forma de manifestação ou troca afetiva. "O homem que faz sexo com um 'homem' de verdade" sente-se frustrado pela ausência de afetividade, porém, extremamente estimulado sexualmente por ter um parceiro com características tão masculinas.

2. "O rapaz que quer transar com um cara que não seja gay" tem 29 anos, e conta que sua grande fantasia sexual é "transar com um cara que não seja gay". Nessa fantasia, percebe que há a vontade de dominar: ainda que aparentemente "o rapaz que quer transar com um cara que não fosse gay"; fosse, na fantasia, a pessoa sexualmente dominada, conseguir que um homem heterossexual mantenha uma relação homossexual seria uma forma de submetê-lo a esse desejo, ou pelo menos, "o rapaz que quer transar com um cara que não seja gay" sentir-se-ia irresistivel- 
mente desejado (o outro seria dominado pelo desejo irresistível provocado pelo "rapaz que quer transar com um cara que não fosse gay"). "O rapaz que quer transar com um cara que não seja gay" revela que só tem interesse em se relacionar, sexual ou amorosamente, com homens que não sejam afeminados e que tenham um pênis 'mais avantajado'.

3. "O homem que queria dormir abraçado, só dormir", na época desse episódio, tinha cerca de 40 anos. Desde jovem, sempre manteve relações com mulheres e, segundo lembra, nunca teve interesses eróticos por homens: nem jogos eróticos praticou na adolescência com amigos e irmãos. "O homem que queria dormir abraçado, só dormir" narrou a seguinte situação: tendo viajado com duas amigas para um final de semana prolongado, na primeira noite, sentiu vontade de dormir, deitar com uma delas, "apenas dormir, abraçados, bem juntos". Não desejava manter relações sexuais com ela, apenas queria dormir junto. Imediatamente lhe passou pela mente que "se fosse dormir com ela e pelo menos não tentasse 'alguma coisa', com certeza, ela iria pensar que ele não gostava de mulher e que fosse homossexual (bicha, em suas palavras)". Assim, manteve-se distante, não a buscou e se sentiu muito só nessa noite: dormiu sozinho abraçando nada.

Narrativas que destacam a orientação:

4. "O rapaz que teme descubram seus desejos" tinha, no tempo desse episódio, 18 anos. É extremamente contido: procura evitar todo e qualquer contato, até mesmo os triviais contatos sociais, restringindo-se a ter somente os estrita e inevitavelmente necessários. Com muita dificuldade, "o rapaz que teme descubram seus desejos" consegue contar que percebe seus desejos por pessoas do mesmo sexo, todos ocorridos apenas na percepção da excitação, pois "o rapaz que teme descubram seus desejos" nunca teve experiência sexual efetiva: conta, a custo, ter tido apenas um evento de jogos eróticos com um primo da mesma idade, apenas com manipulações e toques. Não aceita que seja homossexual, nem mesmo que possa a vir ter relações com outro homem. Sua angústia decorre de se sentir o tempo todo observado e analisado (como se as pessoas soubessem de seu segredo) e tem pavor só de imaginar que algum dia alguém possa vir a conhecer seu "segredo": qualquer chacota, qualquer fala ou ocorrência relacionada a sexo, "o rapaz que teme descubram seus desejos" imagina estejam se referindo a ele e a seu segredo.

5. "O homem que nunca transou", 32 anos, superior completo. Nunca teve relações sexuais, ou qualquer experiência sexual ou amorosa mais completa. Diz que agora aceita seus desejos homossexuais, o que não acontecia durante toda a sua adolescência. Conta passagens de sua vida nas quais se apaixonou por homens que não retribuíam seu interesse: ou por não terem interesse homoerótico ou porque já tinham parceiro ou, por simplesmente, não se interessarem eroticamente pelo "homem que nunca transou". Em sua fala, são percebidos os referenciais idealiza- 
dos e romantizados que tem sobre relacionamento amoroso. Diz se envergonhar de ser "virgem", porém continua em busca do "grande amor" e só por ele romperá a virgindade: diz que, como por circunstância, manteve-se virgem até agora, só se dispõe a praticar sexo se for por uma "grande paixão".

6. "O rapaz sexualmente intenso", 23 anos, tem relações exclusivamente com mulheres, e comenta que tem muita necessidade de fazer sexo e, portanto, pelas facilidades de seu meio social, por trabalhar em uma grande universidade, e ocupar posição de relativa visibilidade, tem muitas aventuras e parceiras. Destaca, em sua narrativa, que amiúde frequenta ambientes mais diversificados e liberais, frequentado também por rapazes homossexuais e "o rapaz sexualmente intenso" gosta de dançar de modo bastante "teatral" (exagerado) e expansivo, o que gera, muitas vezes, a impressão, nesses rapazes, de que é homossexual. "O rapaz sexualmente intenso" percebe "olhares" e o interesse sexual que provoca nesses homens. Chegou mesmo a receber elogios e convites mais explícitos. Tais fatos não o incomodam, pelo contrário, pois, apesar de não manifestar vontade de se relacionar com homens, tem prazer em ser olhado com desejo por outros homens quando dança.

Narrativas que destacam a distinção entre orientação e identidade:

7. "O homem que gosta de aventuras com rapazes rudes e desconhecidos" relata que "mantém vida dupla": é casado, pai de dois filhos pequenos, de quem diz gostar muito. Seu casamento é bastante bom e estável, tendo muito bom nível socioeconômico. No entanto, "o homem que gosta de aventuras com rapazes rudes e desconhecidos" sente muita necessidade de manter relações sexuais com garotos e, assim, quase que semanalmente, procura rapazes de programa, de forma anônima, para satisfazer suas necessidades sexuais. Esses seus parceiros, para atender suas fantasias, devem ser viris, masculinos, quase rudes e de classe social mais bai$\mathrm{xa}$, por isso, procura rapazes para os quais tenha que pagar para fazer sexo.

8. "O homem que sai com homens em encontros rápidos", na época com 28 anos, conta que gosta de encontros sexuais com homens e intencionalmente os busca em locais de encontros homossexuais. Não estabelece relação afetiva, nem amistosa com esses parceiros: todos eventuais, são quase anônimos. Interessa-se apenas pelo "órgão masculino": quer ser dominado e penetrado, nada mais. Relaciona-se amorosa e sexualmente com mulheres: "o homem que sai com homens em encontros rápidos" faz questão que suas parceiras sejam mulheres bonitas e interessantes; seu comprometimento afetivo com elas é legítimo e assim procura, de fato, criar relacionamento conjugal estável e estruturado. Para a sua última companheira, com quem está morando, revelou ser "bissexual" ou, pelo menos, que "tem fases bissexuais".

Narrativas com foco em identidade e/ou que articulam identidade com comportamento e/ou orientação: 
9. "O homem que acha estranho não se sentir nem querer ser mulher" tem 28 anos. Narrou que, de certa forma, sente-se confuso, pois, conhecendo e reconhecendo seus desejos, e até atos homossexuais, acha estranho "sentir-se bastante homem", "gostar de ser homem", ser bastante identificado com valores e comportamentos masculinos, gostar de se vestir e se comportar como homem. Na sua imaginação, pelo fato de ser homossexual, deveria sentir-se mais "feminino", deveria "querer ser mulher". Não acha estranha sua sexualidade, estranha apenas esse aspecto: gosta de homens que gostam de ser homens e que gostam de homens. $E$ "o homem que acha estranho não se sentir nem querer ser mulher" gosta de ser homem.

10. "O rapaz que sai de casa e perambula pelas ruas para esconder da família sua relação amorosa", 31 anos, mantém relacionamento sexual e amoroso com outro rapaz, e coabitam há cerca de três anos. Pelo fato de os familiares de seu parceiro não saberem da relação, e por estes frequentarem bastante a casa (ele e seu parceiro moram em um apartamento pertencente à família deste), "o rapaz que sai de casa e perambula pelas ruas para esconder da família sua relação amorosa" tem que, muitas vezes, "sair de casa" e passar algumas horas na rua, para que a relação não se faça notar, para que os familiares não "descubram", nem desconfiem de nada. Isso acaba interferindo na relação e na própria avaliação que "o rapaz que sai de casa e perambula pelas ruas para esconder da família sua relação amorosa" faz de si e da própria relação que mantém.

11. "O homem que frequenta a zona de travestis" tinha, na época, 29 anos, é casado, e acaba de nascer seu segundo filho. Tem bastante identidade com o papel de pai, e muita satisfação em exercer suas funções de cuidar e educar seus filhos (dois meninos). Comenta que tem uma vida sexual bastante ativa com sua esposa, porém, queixa-se ser ela um tanto ciumenta e controladora, e fazer sexo de maneira mais convencional. Eventualmente, "o homem que frequenta a zona de travestis" tem aventuras extraconjugais. Sente-se um tanto culpado, pois amiúde sente forte necessidade, quase "incontrolável", em manter relações com travestis. Busca-os para satisfazer seus impulsos, e diz sentir muita excitação na obtenção de prazer de forma mais clandestina e por frequentar as casas ou zonas de prostituição ("meio submundo"). Destaca ter muita satisfação em ser dominado sexualmente pelos travestis. "O homem que frequenta a zona de travestis" não se considera homossexual, ainda que perceba que seus desejos não são tão convencionais.

12." O rapaz que trouxe o parceiro para a família", 24 anos, mantém uma relação amorosa estável com outro rapaz de idade assemelhada. Revelou à mãe e às irmãs sua orientação sexual, e faz questão que seu parceiro frequente sua casa e conviva com seus familiares, e vice-versa. "O rapaz que trouxe o parceiro para a família" diz se sentir muito satisfeito por ser homossexual, e suas questões e inquietações estão voltadas à realização profissional e à qualidade da relação amorosa.

13. "O homem submisso e dominado por outro homem há muitos anos" tem 48 anos, e mantém um "caso" amoroso com um mesmo homem desde a adolescência, 
quando tinha 15 anos. De si, "o homem submisso e dominado por outro homem há muitos anos" diz, com certo constrangimento, ser homossexual e que gosta de se vestir de mulher em festas e já fez, por diversão, espetáculos como transformista (travesti). Esse seu parceiro é casado há muitos anos, e "o homem submisso e dominado por outro homem há muitos anos" diz ser muito amigo de sua esposa e é até padrinho de seu primeiro filho. Esse seu parceiro lhe conta que tem aventuras extraconjugais com mulheres e outros homens (o que incomoda muito "o homem submisso e dominado por outro homem há muitos anos": as mulheres, pela esposa e os homens, por si mesmo). Este "homem submisso e dominado por outro homem há muitos anos" também, eventualmente, tem aventuras com outros homens, e, inclusive, atualmente, começa a se envolver com um rapaz bem mais jovem. É inseguro diante de aceitar sua sexualidade, pois este velho parceiro, que exerce muita influência em seu modo de pensar, insiste em considerar a homossexualidade um desvio ("uma coisa errada").

Também foram tomados, nas considerações finais, como elementos para a análise, articulação e explicitação o romance $O$ beijo da mulher-aranha, de Manoel Puig (2003), e o texto teatral O beijo no asfalto, de Nelson Rodrigues (2004). Como obras de arte, são representantes da realidade humana e, nessa condição, na condição de porta-vozes dessa realidade, foram tratados e incorporados ao trabalho. Ainda que ambas as obras tenham versões cinematográficas - O beijo no asfalto, produção brasileira de 1980, dirigido por Bruno Barreto, com roteiro de Doc Comparato, e $O$ beijo da mulher-aranha, produção Brasil/Estados Unidos de 1985, dirigido por Hector Babenco e adaptado por Leonard Schrader -, para este trabalho, foram tomados exclusivamente os textos originais.

\section{Análise e considerações finais}

\section{Acerca dos dois beijos}

Em O beijo da mulher-aranha, de Manuel Puig, há apenas dois personagens: Molina, um declarado e afetado homossexual, preso acusado de corrupção de menores; na mesma cela, Valentin, um intelectual de esquerda, talvez revolucionário, membro de uma organização militante. A história se passa durante o período militar na Argentina.

Esses homens conversam, contam suas histórias. Molina, mais fantasioso, narra filmes a que assistiu ou que inventa ali mesmo. Daí o "Beijo da Mulher-Aranha", protagonista de um roteiro qualquer em um filme B de aventura. Essas vidas se enredam e cada um conhece e é iniciado no universo do outro. Molina, fazendo-se passar por colaboracionista, consegue mantimentos e privilégios com o diretor da prisão, cuida de Valentin, e termina comprometendo-se em levar uma mensagem quando sair da prisão. Valentin conhece e compartilha da fantasia e da sensibilidade de Molina. Tornam-se parceiros e, de formas distintas, um transforma o outro: Molina conhece e começa a lutar e Valentin conhece e começa a amar. Política e sexo se cruzam. 
No texto, as referências à sexualidade de Valentin são claramente heterossexuais, porém, por qualquer razão, pelas circunstâncias, ele, em determinado momento, tem uma relação sexual com Molina, este sim declarado e assumido homossexual. $\mathrm{O}$ autor não recorre a qualquer outro motivo para justificar esse comportamento de Valentin: as circunstâncias já bastam. É absolutamente aceitável e compreensível para o leitor que tal fato simplesmente aconteça. É verossímil que um homem que por toda sua vida tenha tido uma conduta heterossexual, em determinado contexto, por circunstância qualquer, realize um ato homossexual, tenha um comportamento homossexual. Para compreensão desse fato, não há a necessidade de se imaginar ou estimar a existência de um "desejo" homossexual inconsciente ou uma tendência homossexual reprimida que pudesse, nessa hora, se manifestar. O comportamento homossexual, ainda que circunstancial, é compreensível em si mesmo, sem a necessidade de qualquer outro motivo que não ele mesmo.

O beijo no asfalto, peça de Nelson Rodrigues, escrita e encenada em 1961, conta a história de um homem, Arandir, que presencia o atropelamento de um homem no centro do Rio de Janeiro, às 5 horas da tarde. Agonizante, o atropelado lhe pede um beijo. Arandir o beija. Testemunham essa cena centenas de pessoas, mas, principalmente, Aprígio, seu sogro, pai de Selminha, sua mulher, e Amado Ribeiro, um inescrupuloso e ambicioso repórter. Esse jornalista, mancomunado com policiais corruptos, resolve transformar "o beijo" em grande evento jornalístico, visando, é claro, fama e venda. Consegue fazer a viúva, chantageada, afirmar se conhecerem de mais tempo, intimamente, pois até banho teriam tomado juntos, Arandir e o atropelado.

O jornal transforma Arandir em amante do atropelado, e os colegas, conhecidos e vizinhos, conduzidos pelas "informações" e "interpretações", passam a ver Arandir como, de fato, amante (homossexual) do atropelado. Mais tarde, o jornal o torna assassino: na verdade, segundo o jornalista, Arandir teria empurrado o "amante" para que fosse atropelado. Tratado como se fosse homossexual, Arandir é abandonado pela esposa que, envolvida pelas tramas das notícias e dos comentários, termina por suspeitar de sexualidade do marido. A cunhada de Arandir se declara estar de há muito apaixonada por ele, e afirma aceitar, por amor, sua "sexualidade suspeita". O ápice da tragédia acontece quando Arandir é assassinado pelo próprio sogro que, na última cena, revela ter sido sempre apaixonado por ele e não suportar a ideia de ele haver beijado outro homem. Em $O$ beijo no asfalto, identidade e orientação são atribuídas a partir de um ato alegadamente homossexual.

\section{Acerca das narrativas}

No transcorrer da análise das narrativas compostas a partir de relato de homens no consultório de psicologia, pudemos constatar que, quanto à homossexualidade masculina, os três componentes considerados - comportamento, orientação e identidade - nem sempre estão conjuntamente presentes nas ocorrências homossexuais, e mostrar que cada um desses componentes, por si só, já caracteriza uma ocorrência homossexual. Afastamo-nos da tradição que estabelece certa hierarquia entre esses 
componentes e assim demonstrar que cada um desses componentes tem relativa autonomia em relação aos outros e pode ocorrer isoladamente. Habituamos a pensar a homossexualidade como uma homogeneidade, quer na forma como ela se dá, quer na dinâmica psíquica e social dos indivíduos homossexuais (Costa, 1992; 1998b). Contudo, a homossexualidade é diversa em suas manifestações, apenas porque são diversas as manifestações sexuais da humanidade.

Podemos considerar os componentes aqui tratados - comportamento, orientação e identidade - como canais para essa diversidade aflorar. Não há qualquer necessidade teórica ou prática de se considerar uma delas mais importante do que as outras, nem mesmo considerar que obrigatoriamente deverão estar presentes, concomitante ou conjuntamente. O sujeito é diverso, embora isso possa nos causar espanto ou incômodo, pois há tempos consideramos o sujeito uno e consolidado: aprendemos a pensar a unicidade e não a diversidade.

Nas narrativas consideradas para a pesquisa, confirmam-se a diversidade e a imprevisibilidade das possibilidades de realização do ser humano, pois além de haver diversidade nas práticas e nas escolhas sexuais, também são diversas as formas como essas escolhas se manifestam. Perceber que a ocorrência de situações em que não obrigatoriamente estão presentes, conjunta e concomitantemente, comportamento, orientação e identidade é reconhecer mais uma dimensão da diversidade, evitando estabelecer qualquer hierarquia entre esses três componentes e assim evitar a catalogação, outra forma comum de discriminação.

Comportamento, orientação e identidade são componentes da sexualidade que mantêm, entre si, relativa independência, tanto que não estão, conjunta e concomitantemente, presentes em todas as experiências sexuais narradas. Com esta pesquisa, buscou-se uma maior compreensão desses fenômenos e também contribuir para a superação, mediante o entendimento dos mecanismos geradores e mantenedores dos preconceitos, estigmas e discriminações.

\section{Referências}

Almeida M. B. \& Soares, A. S. (2012). O futebol no banco dos réus: caso de homofobia. Movimento, 18(1), 301-321. Recuperado em 20 fevereiro, 2015, de http:// www.seer.ufrgs.br/Movimento/article/view/20826/17386.

Arendt, H. (2014). A condição humana. Rio de Janeiro: Forense Universitária.

Badinter, E. (1993). XY: sobre a identidade masculina. Rio de Janeiro: Nova Fronteira.

Barroso, L. R. (2011). Diferentes mas iguais: o reconhecimento jurídico das relações homoafetivas no Brasil. Revista Brasileira de Direito Constitucional, 17, 105-138.

Bly, R. (2004). João de Ferro: um livro sobre homens. Rio de Janeiro: Campus.

Bourdieu, P. (2014). A dominação masculina. Rio de Janeiro: Record/Bestbolso. 
Costa, J. F. (1992). A inocência e o vício: estudos sobre o homoerotismo. Rio de Janeiro: Relume-Dumará.

Costa, J. F. (1998a). Sem fraude nem favor: estudos sobre o amor romântico. Rio de Janeiro: Rocco.

Costa, J. F. (1998b). A questão Psicanalítica da identidade sexual. In R. Graña (Ed.). Homossexualidade: formulações psicanalíticas atuais. Porto Alegre: Artes Médicas.

Diniz A. P. R., Carrieri, A. P, Gandra, G., \& Bicalho, R. (2013). Políticas de diversidade nas organizações: as relações de trabalho comentadas por trabalhadores homossexuais. Revista Economia \& Gestão da PUC Minas, 13(31). Recuperado em 20 fevereiro, 2015, de http://200.229.32.55/index.php/economiaegestao/article/view/P.1984-6606.2013v13n31p93.

Dover, K. J. (2007). A homossexualidade na Grécia antiga. São Paulo: Nova Alexandria. Foucault, M. (2014). História da sexualidade I: a vontade de saber. Rio de Janeiro: Paz e Terra.

Lopes, J. R. L. (2014). Da dissidência à diferença: direitos dos homossexuais no Brasil da ditadura à democracia. In J. Green \& R. Quinalha (Ed.). Ditadura e homossexualidade: repressão, resistência e a busca da verdade. São Carlos: EduFSCar.

Marques, L. (2014). Homossexualidade, cultura e representações sociais: um breve percurso sobre a história de sua (des)patologização. Poliantea, 10(18), 227-267. Recuperado em 20 fevereiro, 2015, de http://journal.poligran.edu.co/index.php/ poliantea/article/viewFile/534/479.

Nolasco, S. (2006). De Tarzan a Homer Simpson: banalização e violência em sociedades contemporâneas. Rio de Janeiro: Rocco.

Pereira, A. S., Alfaia, A. J. B., Souza, L. E. C., \& Lima, T. J. S. (2014). Preconceito contra homossexuais no contexto do futebol. Psicologia e Sociedade, 26(3), 737-745. Recuperado em 20 fevereiro, 2015, de http://www.scielo.br/pdf/psoc/v26n3/a22v26n3.pdf.

Puig, M. (2003). O beijo da mulher-aranha. Rio de Janeiro: José Olympio.

Rodrigues, N. (2004). O beijo no asfalto. Rio de Janeiro: Nova Fronteira.

Santos, D. K. (2013). As produções discursivas sobre a homossexualidade e a construção da homofobia: problematizações necessárias à psicologia. Revista Epos, 4(1). Recuperado em 20 fevereiro, 2015, de http://pepsic.bvsalud.org/scielo.php? script=sci_arttext\&pid=S2178-700X2013000100007\&lng=pt\&nrm=iso.

Trevisan, J. S. (1998). Seis balas num buraco só: a crise do masculino. Rio de Janeiro: Record. 